\title{
Analysis and Adaptation of an ESL Reading and Vocabulary Textbook
}

\author{
HU Yan \\ Shanghai Institute of Technology, Shanghai, China
}

\begin{abstract}
Vocabulary and reading have always been the long-time obsession of Chinese teachers in English teaching, yet it may be a new perspective to analyze the teaching methods by SLA principles. However, there are many theories conflicting with each other on how the second language is learnt, thus it is impossible for a textbook to adopt all the SLA theories at the same time. By analyzing the content of a textbook which is guided by some SLA principles, this paper aims to find out how SLA principles are applied in an ESL reading and vocabulary course, and then elaborate on some adaptation of the teaching methods in the classroom teaching practice.
\end{abstract}

Keywords: SLA, ESL, reading and vocabulary textbook

\section{Introduction}

Nowadays we are often at loss when we have to select an appropriate textbook from the numerous prints of textbooks. Among all these books, we find textbooks on reading and vocabulary outnumber others, which we cannot be least surprised about. Vocabulary and reading have always been the long-time obsession of Chinese teachers in English teaching, yet it may be a new perspective to analyze the teaching methods by SLA principles. With an ESL reading and vocabulary textbook at hand, whose text and exercise arrangement render the clue of influences of SLA on it, the writer tries to analyze some principles of SLA underlying the textbook and to explain the adaptation of the textbook the writer made in teaching practice.

\section{Some SLA Theories on Vocabulary Learning}

Second language acquisition (SLA) is the study of how second languages are learned and the factors that influence the process. SLA researchers examine how communicative competence - the ability to interpret the underlying meaning of a message, understand cultural references, use strategies to keep communication from breaking down, and apply the rules of grammar — develops in a second language (Savignon, 1997). They also study nonlinguistic influences on SLA such as age, anxiety, and motivation (Ellis, 1997).

Word knowledge is an essential component of communicative competence, and it is important for production and comprehension in a second language (Coady \& Huckin, 1997). What does it mean to know a word? Vocabulary knowledge is the size of the vocabulary and the depth of vocabulary, which includes knowledge of pronunciation, spelling, multiple meanings, the contexts in which the word can be used, the

HU Yan, associate professor, master, Department of Foreign Language, Shanghai Institute of Technology. 
frequency with which it is used, morphological and syntactical properties, and how the word combines with other words (Qian, 1999).

Recent research has focused on incidental vocabulary — vocabulary that second language learners develop while they are focused on a task other than on learning new words (Gass, 1999). However, learners need to understand about 3,000 word families (e.g., the family of "think" includes think, thinks, thought, thoughtful, and thoughtfully) in order to understand meaning from context (Laufer, 1997). Teachers can help learners build sight vocabulary by teaching word families and using word association activities such as semantic mapping (DeCarrico, 2001). In semantic mapping, teachers identify key terms in a text and learners list other words in the text that relate to the key terms.

Research also suggests that learners gain vocabulary knowledge through extensive reading (Burt, Peyton, \& Adams, 2003). Moreover, reading accompanied by vocabulary building activities can increase vocabulary knowledge (Paribakht \& Wesche, 1997). Teachers should include reading opportunities in class and assist learners by selecting texts that are of high interest and level appropriate. They should preview the key vocabulary in a reading passage, teach high-frequency words, and help learners use dictionaries effectively (Burt, Peyton, \& Adams, 2003).

Memorizing vocabulary is another problem. Harry Bahric (1984) argued that repeating words as strings of sound is low-level processing and badly remembered; working out how words fit in the grammatical structure of the sentence is deeper and leads to better memory using the meaning of words together within the whole meaning of the sentence is the deepest level of processing and ensures the best memory.

\section{Analysis of the Textbook}

Actually there are many theories conflicting with each other on how the second language is learnt, thus it is impossible for a textbook to adopt all the SLA theories at the same time. Instead, it will adopt some and cling to them while contradict with others. Contact U.S.A is exactly that kind. This textbook, edited by Paul Abraham and Daphne Mackey, is a reading and vocabulary text for high-beginning and low-intermediate ESL students. Although its structure and exercise are aimed primarily at developing academic reading skills and vocabulary, its content is highly appropriate for all non-native English speakers, including immigrants, students in higher educational institutions, and students of English in foreign countries.

This book was written on the premise that adult students at this level of English proficiency are able to read and understand more in English than they are able to actively produce. Therefore, although the readings may appear to be difficult for students at this level at first glance, the first analytical exercises are relatively simple, requiring only passive reading and vocabulary skills. These types of reading and vocabulary skills are important for students to develop, particularly because the analysis of a reading beyond their proficiency level is a process that students confront in standardized tests in English. The reading exercises in this book progress from main idea to inference. The following is a general outline of each chapter.

In addition, the book contains reading clues (questions in each chapter with answer and examples in the appendix), vocabulary review tests, and answer keys (both for chapter exercises and the review tests). There is also a score grid on which students may record their results for each section of each chapter. 
A very important characteristic which seems contradicting to many theories is that: It claims prohibition of dictionary. This book was written with the belief that dictionaries are generally a reading inhibitor rather than a reading enhancer. With this in mind, the cardinal rule of the book is NO DICTIONARIES ALLOWED. The meaning of much of the vocabulary is implies within the reading passage, as the students discover when they complete the first vocabulary exercise, which requires them to analyze words within the context of the reading and compare them to other words that they already know. The vocabulary exercise and the inaccessibility of a dictionary force the students to look for meaning within the context, an essential reading skill. This book serves as a vocabulary builder because we reuse the vocabulary throughout the book so that students are forced to recall vocabulary from previous chapters, where it is used in different contexts. This leads to actual acquisition of the words in the text.

\section{Application and Adaptation of the Textbook}

My teaching aims at giving English training to a group of adult student with an intermediate level of English proficiency. To be more specific, the reading course is to help them cultivate a good reading habit and grasp a number of high-proficiency words. Thus my class teaching and activities should adapt to meet their needs and requirement. In the following paragraphs, I will discuss in details how I apply and adapt the text book.

(1) Section 1: This section actually includes a passage which is to be processed by reads, and exercises which demand several reading skills, such as scanning and main idea searching. It is a good idea to do section 1 during class time so that I can check that students do not use the dictionary and that they work at a reasonable pace.

(a) Main idea: Give the students about one and a half to two minutes to find the main idea of the reading, remind them that skimming the first sentence or the first two sentences will suffice for main idea. Then correct this exercise before students go on to next exercise.

(b) Reading: This is a general reading that gives background information and vocabulary. Generally, I give them a limited time rather than letting them reading at their own pace to finish the exercise in this section. Encourage students not to follow the text with their pencils, mouth the words as their read, or fixate on unknown vocabulary items.

(c) Scanning: In order to emphasize reading skills, this exercise may be done before exercise B and be timed. This exercise is used to give students practice in finding specific information quickly.

(d) Vocabulary: This exercise is used to help students determine the meaning of unfamiliar words by examining them in context. Encourage the students to find the words in the reading (the line numbers are given after the words in the exercise). Also emphasize the fact that the term similar is not exactly-it refers to general similarity.

(e) Reading comprehension: It is not necessary to go over the answer to the multiple choice exercises unless the students have specific questions. They should be able to find the correct answer. In addition, they have a further look at the reading comprehension exercise in section 2 .

(2) Section 2: After the students have graded their answers to section 1, they can go on to this more detailed look at the reading. This section includes three kinds of exercise, trying to testing the ability of contextual comprehension of text as well as of vocabulary. 
(a) Vocabulary: The students may find it helpful to look back at the reading or at the vocabulary exercise in section 2 in order to complete this vocabulary exercise. Again no dictionaries may be used.

(b) Reading comprehension: In this last multiple choice reading comprehension check, students should get $90 \%$ of the questions correct.

(c) Question: These questions may be written or be done orally. They serve as a comprehension check, to make sure that the students understand the general meaning of the reading. Students often give too much information by using unnecessary sentences or even whole paragraph from textbook instead of the specific and limited information required by the question. Therefore, it is helpful to ask the students to do the exercise with their books open, but then ask them to give the answer in class with their book closed. When they try to answer from memory, they are more likely to give only the essential information.

(3) Section 3: This section, including a passage to be read and some related exercises, presents a point of view connected to the subject of the chapter. This point of view is used first as timed reading, but teachers are encouraged to use it for discussion.

(a) Timed reading: The four-minute time limit is a general guideline. Teachers should feel to vary it according to the reading abilities of their students. The questions following may want to read the questions first and then scan the reading quickly to find the answer. They are asked to decide if the statements are true, false, or impossible to know from the information and implications given in the reading.

(b) Vocabulary: This vocabulary exercise varies from chapter to chapter in form, but tests the vocabulary given in the timed reading.

(c) Word forms: These word form exercise follow a progression from recognition of differences in the function and form of words in sentences to production of the proper forms. Teachers can decide whether it is necessary to do this exercise or not according to the proficiency of students; as for me, I just overlooked it because of its obvious simplicity for Chinese students. Following is an outline of this section through the book.

(d) Speaking: The speaking activities in the book vary in each chapter. They may be general discussion questions, role plays, or problem-solving exercises. All of them serve to initiate discussion and to provide the students with the necessary vocabulary of forms essential for the discussion. While doing these activities, the students will require the vocabulary introduced in the chapter. Since the Chinese adults are usually reluctant to speak up, I firstly adopted question-answering pattern, which can be solved by finding information from the book, to reduce their anxiety. Gradually, I encouraged them to speak something freely with vocabulary on the blackboard. At last, they even got involved into discussion!

(e) Writing: The writing activities are connected either to the speaking exercises or to the reading clue. They include both controlled and free composition as well as sentence combining and sentence completion exercises. Some of the writing exercises require additional grammatical explanations by the teacher; for example, in chapter 10 , an understanding of the modal auxiliaries is necessary for completion of this exercise. Thus a supplementary explanation on grammatical knowledge and cohesive devise is needed for this section.

\section{Conclusion}

In this paper, I have illustrated how an ESL reading and vocabulary textbook embodied some SLA principles, and how a teacher, in a practical teaching, should adapt to meet the different needs and requirements, 
yet the investigation I have made is far from satisfactory. Being aware of the SLA principle underlying the textbook is not enough. For most teachers, eclecticism may be a better answer to the vocabulary and reading teaching.

\section{References}

Abraham, P., \& Mackey, D. (1996). Contact U.S.A. New Jersey: Prentice-Hall Inc..

Bahrick, H. P. (1984). Semantic memory content in permastore: Fifty years of memory for Spanish learned in school. Journal of Experimental Psychology: General, 114(1), 1-30.

Burt, M., Peyton, J. K., \& Adams, R. (2003). Reading and adult English language learners: A review of the research. Washington, DC: Center for Applied Linguistics.

Coady, J., \& Huckin, T. (Eds.). (1997). Second language vocabulary acquisition: A rationale for pedagogy. United Kingdom: Cambridge University Press.

Ellis, R. (1997). Second language acquisition. New York: Oxford University Press.

DeCarrico, J. (2001). Vocabulary learning and teaching. In M. Celce-Murcia (Ed.), Teaching English as a second and foreign language (pp. 285-299). Boston: Heinle \& Heinle.

Gass, S. M. (1999). Discussion: Incidental vocabulary learning. Studies in Second Language Acquisition, 21, $319-333$.

Laufer, B. (1997). The lexical plight in second language reading: Words you don't know, words you think you know, and words you can't guess. In J. Coady and T. Huckin (Eds.), Second language vocabulary acquisition: A rationale for pedagogy (pp. 20-34). United Kingdom: Cambridge University Press.

Paribakht, T. S., \& Wesche, M. (1997). Vocabulary enhancement activities and reading for meaning in second language vocabulary acquisition. In J. Coady and T. Huckin (Eds.), Second language vocabulary acquisition: A rationale for pedagogy (pp. 174-200). United Kingdom: Cambridge University Press.

Qian, D. D. (1999). Assessing the roles of depth and breadth of vocabulary knowledge in reading comprehension. Canadian Modern Language Journal, 56, 262-305.

Savignon, S. (1997). Communicative competence: Theory and classroom practice. New York: McGraw-Hill. 